\title{
Intentional limited pulmonary resection for peripheral T1 N0 MO small-sized lung cancer
}

\author{
Teruaki Koike, MD \\ Yasushi Yamato, MD \\ Katsuo Yoshiya, MD \\ Takehiko Shimoyama, MD \\ Ryuta Suzuki, MD
}

Objective: The present study was undertaken to demonstrate that limited pulmonary resection for peripheral small-sized lung cancer yields outcomes not inferior to those of lobectomy.

Methods: During the 9-year period from 1992 to 2000, patients with cT1 N0 M0 peripheral non-small cell lung cancer whose maximum tumor diameter was $2 \mathrm{~cm}$ or less on diagnostic imaging and in whom lobectomy was determined to be feasible were treated with limited resection if the patient consented to the procedure and with lobectomy if consent to limited resection was not obtained. The survival and clinical outcome of the patients whose tumors were postoperatively staged as pT1 N0 M0 were compared between the limited resection group $(n=74)$ and the lobectomy group $(\mathrm{n}=159)$.

Results: The limited resection group consisted of 60 patients treated with segmentectomy and 14 patients treated with wedge resection. Among patients followed up for a mean period of 52 months after the operation, neither the 3-year nor 5-year survivals differed significantly between the limited resection group (3-year survival, 94.0\%; 5-year survival, 89.1\%) and the lobectomy group (3-year survival, 97.0\%; 5-year survival, 90.1\%). Postoperative tumor recurrence was noted in 5 patients after limited resection and in 9 patients after lobectomy, and the difference in the incidence of postoperative recurrence between the 2 groups was not significant.

Conclusions: The results of this study indicate that in patients with peripheral T1 N0 M0 non-small cell lung cancer whose maximum tumor diameter was $2 \mathrm{~cm}$ or less, the outcome of limited pulmonary resection is comparable with that of pulmonary lobectomy.

From the Division of Chest Surgery, Niigata Cancer Center Hospital, Niigata, Japan.

Received for publication April 26, 2002; revisions requested July 8, 2002; revisions received July 22, 2002; accepted for publication Aug 15, 2002.

Address for reprints: Teruaki Koike, MD, Division of Chest Surgery, Niigata Cancer Center Hospital, 2-15-3 Kawagishi-cho, Niigata, 951-8566 Japan (E-mail koike@niigata-cc.niigata.niigata.jp).

J Thorac Cardiovasc Surg 2003;125:924-8

Copyright () 2003 by The American Association for Thoracic Surgery

$0022-5223 / 2003 \$ 30.00+0$

doi: $10.1067 / \mathrm{mtc} .2003 .156$

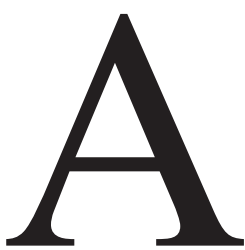

lthough lobectomy is often used as the surgical procedure to treat T1 N0 non-small cell lung cancer (NSCLC), lesser pulmonary resection, such as segmentectomy or wedge resection, has theoretical advantages in terms of the ability of patients to withstand further pulmonary resection in the future if a second primary lung cancer should develop and the need to preserve pulmonary function and reduce perioperative mortality and morbidity. ${ }^{1}$ The Lung Cancer Study Group conducted a randomized trial of limited lung resection and lobectomy and found a higher postoperative mortality and incidence of recurrence in the limited resection group. On the basis of these findings, the group reported that lobectomy should be performed even for T1 N0 M0 NSCLC. ${ }^{2}$

However, as a result of the widespread adoption of a lung cancer mass-screening system $^{3}$ and the introduction of chest computed tomographic scanning into the system, ${ }^{4}$ there has been a marked increase in the incidence of small-sized lung 
TABLE 1. Background

\begin{tabular}{|c|c|c|c|}
\hline & Limited resection & Lobectomy & $P$ value \\
\hline No. of patients & 74 & 159 & \\
\hline $\operatorname{Sex}(M / F)$ & $38 / 36$ & $80 / 79$ & .77 \\
\hline Age (y) & $64.2 \pm 7.2$ & $65.3 \pm 9.5$ & .37 \\
\hline Tumor size $(\mathrm{cm})$ & $1.5 \pm 0.4$ & $1.7 \pm 0.4$ & .001 \\
\hline \multicolumn{4}{|l|}{ Pulmonary function } \\
\hline $\mathrm{VC} / \mathrm{m}^{2}(\mathrm{~L})$ & $2.07 \pm 0.44$ & $1.99 \pm 0.41$ & .22 \\
\hline $\mathrm{FEV}_{1.0} / \mathrm{m}^{2}(\mathrm{~L})$ & $1.48 \pm 0.36$ & $1.46 \pm 0.32$ & .75 \\
\hline Histologic type & & & .54 \\
\hline Adenocarcinoma & 68 & 141 & \\
\hline Squamous cell carcinoma & 5 & 17 & \\
\hline Other & 1 & 1 & \\
\hline Lymph node dissection & & & .63 \\
\hline Complete & 48 & 98 & \\
\hline Incomplete & 26 & 61 & \\
\hline
\end{tabular}

$V C$, Vital capacity; FEV, forced expiratory volume.

cancers in Japan. ${ }^{5}$ The possibility of cure by performing limited resection for small-sized peripheral lung cancer has thus begun to receive close attention.

On the basis of our experience with limited resection in poor-risk patients, we concluded that it might be possible to radically cure peripheral small-sized lung cancer by means of limited resection. In 1992, we began a pilot study of limited resection for patients with cT1 N0 M0 NSCLC whose maximum tumor diameter was $2 \mathrm{~cm}$ or less on diagnostic imaging who provided informed consent for the procedure.

This article retrospectively assesses the results of limited resection and standard lobectomy in patients with T1 N0 NSCLC (tumor diameter of $\leq 2 \mathrm{~cm}$ ) at the Niigata Cancer Center.

\section{Patients and Methods}

Expecting that intentional limited resection for small-sized lung cancer might provide an even postoperative survival compared with lobectomy, in January 1992, we began enrolling patients who satisfied the following criteria as candidates for this procedure: (1) cT1 N0 M0 peripheral lung cancer with a tumor located relatively closer to the visceral pleura than to the hilum; (2) maximum tumor diameter of $2 \mathrm{~cm}$ or less as measured on plain chest $\mathrm{x}$-ray film or chest computed tomographic images; (3) no history of previous treatment; (4) NSCLC; (5) general condition and respiratory function adequate for lobectomy; and (6) tumor location suitable for limited resection (ie, the tumor was completely resectable with 1 or 3 segmentectomies, excluding the one located in the right middle lobe).

A total of 268 candidates satisfied these criteria, and 80 of them gave consent for limited resection. Limited resection was performed in 76 patients, whereas the procedure was changed to lobectomy in 4 patients in whom intraoperatively positive lymph node metastasis was detected. Standard lobectomy was performed in those from whom consent to limited resection was not obtained. The subjects of this retrospective study were patients who satisfied the above criteria, who were treated surgically at the Niigata
Cancer Center during the 9-year period from January 1992 to December 2000, and whose tumors were postoperatively staged as pT1 N0 M0 NSCLC (maximum tumor diameter in the resected specimen of $\leq 2 \mathrm{~cm}$ ).

The following patients were excluded from this study: 14 patients with pathologic positive lymph node metastasis; 9 patients with a maximum tumor diameter measured in the resected specimens of greater than $2 \mathrm{~cm}$; 6 patients with positive lymph node metastasis and large tumor size; 4 patients with pleural invasion; and 2 patients with dissemination.

The operative procedure was limited resection in 74 patients and pulmonary lobectomy in 159 patients. Local recurrence was defined as recurrence at the surgical margin or within the operated thoracic cavity (eg, malignant pleural effusion or lymph node metastasis). Intrapulmonary metastasis or metastasis to other organs was defined as distant metastasis.

The significance of differences in background variables between the 2 groups was tested by using the $\chi^{2}$ or unpaired $t$ tests. Survival and disease-free survival period were calculated by using the Kaplan-Meier method. The significance of differences in these rates was tested by using the log-rank test.

\section{Results}

In the limited resection group the procedure of first choice was segmentectomy. Incidentally, wedge resection was selected when the space was $2 \mathrm{~cm}$ or wider between the tumor edge and a surgical margin. Segmentectomy was performed in 60 patients, and wedge resection was performed in 14 patients (Table 1). Lymph node dissection consisted of complete hilar and mediastinal lymphadenectomy in 48 patients and incomplete lymphadenectomy in 26 patients. In these 26 patients mediastinal lymphadenectomy was omitted because no lymph node metastasis was detected after sampling of the hilar lymph node. Recently, in Japan, when the operator judges intraoperatively that there is no lymph node metastasis in cases of early stage lung cancer, mediastinal lymphadenectomy is performed less frequently. Among the background variables, male/female ratio, age, 


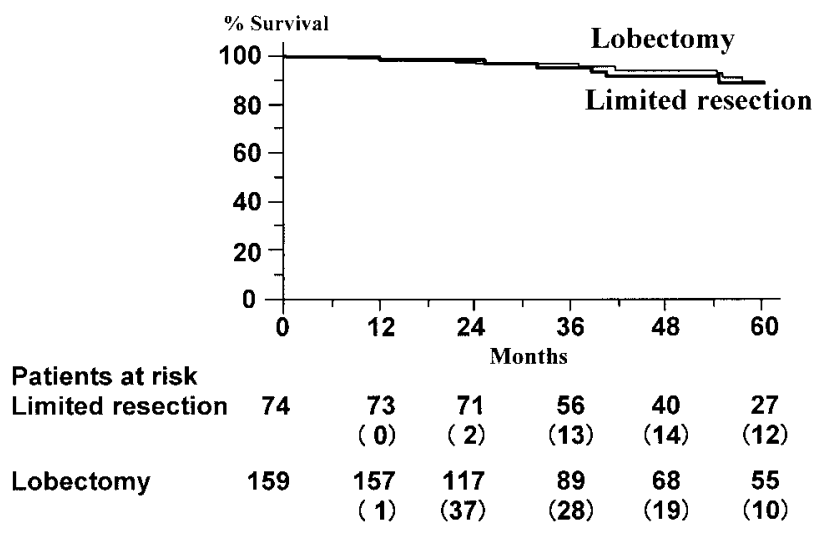

Figure 1. Postoperative survival curve. There was no significant difference in the survivals of patients treated with limited resection and those treated with lobectomy $(P=.91)$. Figures given in parentheses indicate censored cases.

TABLE 2. Clinical outcome

\begin{tabular}{|c|c|c|c|}
\hline & Limited resection & Lobectomy & $P$ value \\
\hline Follow-up period (d) & $1624 \pm 681$ & $1532 \pm 966$ & .47 \\
\hline Recurrence & 5 & 9 & .74 \\
\hline Local & 2 & 2 & .42 \\
\hline Distant & 3 & 7 & .90 \\
\hline Death & 8 & 16 & .86 \\
\hline Lung cancer & 5 & 8 & .59 \\
\hline Other disease & 3 & 8 & .73 \\
\hline
\end{tabular}

pulmonary function, and histologic type did not differ significantly between the limited resection group and the lobectomy group, but maximum tumor diameter measured in the resected specimens was significantly smaller in the limited resection group $(1.5 \pm 0.5 \mathrm{~cm})$ than in the lobectomy group $(1.7 \pm 0.5 \mathrm{~cm})$. There were no severe cardiovascular or comorbid factors in either group.

Follow-up was performed every 3 months for 5 years after the operation, with chest radiography and hematologic examination, and chest computed tomographic scans were performed every year. The patients were followed up for 8 to 120 months (mean, 52 months). The 3-year and 5-year survivals were slightly higher in the lobectomy group ( $97.0 \%$ at 3 years and $90.1 \%$ at 5 years) than in the limited resection group ( $94.0 \%$ and $89.1 \%$, respectively), but the differences were not statistically significant (Figure 1). The 95\% confidence interval of the survival curve of patients treated with lobectomy was $82.2 \%$ to $97.9 \%$, and that of patients treated with limited resection was $77.3 \%$ to $100 \%$.

Recurrence was detected in 5 patients in the limited resection group, including 2 cases of local recurrence (one case each of malignant pleural effusion and ipsilateral mediastinal lymph node recurrence). Recurrence was diagnosed in 9 patients in the lobectomy group, including 2

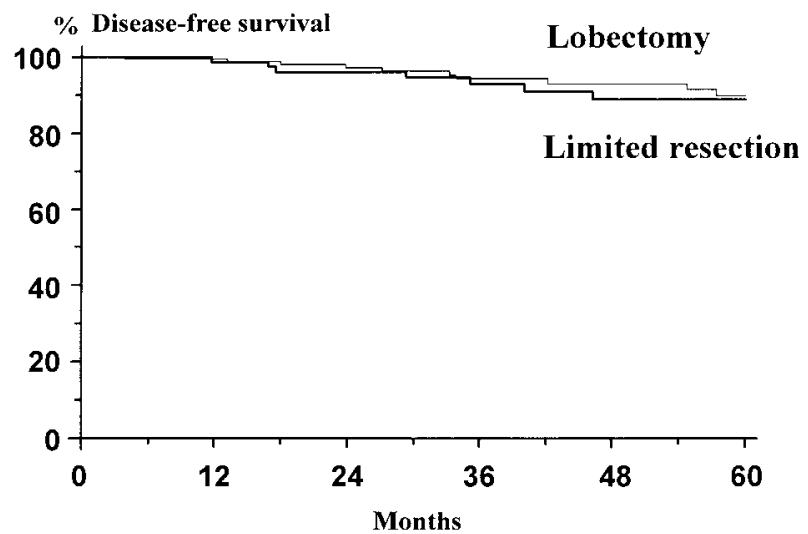

Figure 2. Postoperative disease-free survival curve. There was no significant difference in disease-free survivals of patients treated with limited resection and those treated with lobectomy $(P=.93)$.

cases of local recurrence (one case each of ipsilateral mediastinal lymph node recurrence and malignant pleural effusion), as shown in Table 2. No perioperative deaths were recorded in either group. To date, 8 patients in the limited resection group have died (including 5 deaths related to the primary cancer), and 16 patients in the lobectomy group have died (including 8 deaths related to the primary cancer). The mortality rate did not differ significantly in the 2 groups, and as shown in Figure 2, there were no significant differences in the 3-year and 5-year disease-free survivals (limited resection group, $92.7 \%$ at 3 years and $88.7 \%$ at 5 years; lobectomy group, $94.2 \%$ at 3 years and $89.8 \%$ at 5 years).

\section{Discussion}

Lobectomy is usually performed to treat stage I peripheral lung cancer. Limited pulmonary resection has been attempted by many surgeons in patients with minimal tumor invasion, expecting that this procedure would result in radical cure of the cancer. Because limited resection imposes less operative stress on the patient (smaller lung volume resected and shorter operation time), it has primarily been performed in patients in relatively poor general condition due to compromised lung function. ${ }^{1}$

Errett and coworkers ${ }^{6}$ performed wedge resection in 100 poor-risk patients with stage I lung cancer (elderly patients and patients with compromised lung function) and reported that the 6-year survival in these patients (69\%) did not differ significantly from that of patients treated with lobectomy (75\%) (Table 3).2,6-12

Pastorino and coworkers ${ }^{7}$ also performed limited resection in 61 poor-risk patients with stage I lung cancer and then reported a 5-year survival of 55\% in this group compared with $49 \%$ in a pulmonary lobectomy group. The patients with $\mathrm{T} 1$ disease treated with limited resection in 
TABLE 3. Survival and local recurrence rate in reported series of limited resection

\begin{tabular}{|c|c|c|c|c|c|c|c|}
\hline \multirow[b]{2}{*}{ Reference/period } & \multirow[b]{2}{*}{ Subject } & \multicolumn{3}{|c|}{ Limited resection } & \multicolumn{3}{|c|}{ Lobectomy } \\
\hline & & $\begin{array}{c}\text { No. of } \\
\text { patients }\end{array}$ & $\begin{array}{c}5 \mathrm{y} \\
\text { survival (\%) }\end{array}$ & $\begin{array}{c}\text { Local } \\
\text { recurrence (\%) }\end{array}$ & $\begin{array}{c}\text { No. of } \\
\text { patients }\end{array}$ & $\begin{array}{c}5 \text { y } \\
\text { survival (\%) }\end{array}$ & $\begin{array}{c}\text { Local recurrence } \\
(\%)\end{array}$ \\
\hline Erreett ${ }^{6} 1965-{ }^{\prime} 82$ & Stage I (C) & 100 & 69 & NM & 97 & 75 & NM \\
\hline Pastorino7 1971-'88 & Stage I (C) & 61 & 55 & 5 & 411 & 49 & 5 \\
\hline Read8 1966-'88 & T1 No MO (I) & 113 & about 84 & 4.4 & 131 & about 74 & 11.5 \\
\hline Warren' $1980-{ }^{\prime} 88$ & Stage I (I) & 66 & about 43 & 22.7 & 103 & about 67 & 4.9 \\
\hline LCSG² 1982-'88 & T1 No Mo (R) & 122 & 44 & 17.2 & 125 & 65 & 6.4 \\
\hline Landreneau10 1989-'94 & T1 NO MO (C) & $\begin{array}{l}42^{*} \\
60 \dagger\end{array}$ & $\begin{array}{l}58 \\
65\end{array}$ & $\begin{array}{l}24 \\
16\end{array}$ & 117 & 70 & 9 \\
\hline Tsubota11 1992-'94 & T1 No Moł (I) & 55 & $91 \S$ & 5.5 & & NM & NM \\
\hline Kodama ${ }^{12} 1985-' 96$ & T1 No MO (I) & 46 & 93 & 2.2 & 77 & 88 & 1.3 \\
\hline Koike 1992-2000 & T1 No MO‡ (I) & 74 & 89 & 2.7 & 159 & 90 & 1.3 \\
\hline
\end{tabular}

$C$, Compromised, I, intentional; $R$, randomized controlled trial; $N M$, not mentioned.

*Open wedge resection.

tVideo-assisted wedge resection.

$\ddagger$ Maximum tumor diameter $\leq 2 \mathrm{~cm}$.

$\S$ Death rate related to primary lung cancer.

particular had a higher 5-year survival (73\%) than those treated with lobectomy (55\%), and on the basis of these results, they reported that limited resection is an effective procedure for the treatment of $\mathrm{T} 1$ disease.

Read and associates ${ }^{8}$ intentionally performed limited resection in low-risk patients, and they reported a higher 5-year survival in 113 patients with T1 N0 M0 lung cancer treated with limited resection than in 131 similar patients treated with lobectomy.

Warren and colleagues ${ }^{9}$ compared 66 patients with stage I disease treated by means of limited resection with 103 patients with stage I disease treated by means of lobectomy and reported that the 5-year survival was significantly higher in the lobectomy group when the tumor diameter was $3 \mathrm{~cm}$ or greater but that lobectomy was not superior when the maximum tumor diameter was less than $3 \mathrm{~cm}$. Their findings suggest that limited resection can be used as the standard procedure for the surgical treatment of T1 N0 lung cancer.

However, in 1995, after conducting a randomized controlled trial involving limited resection and lobectomy, the Lung Cancer Study Group concluded that lobectomy should be performed as the standard procedure for all patients with T1 N0 disease because limited resection is associated with higher mortality and local recurrence rates. ${ }^{2}$

Landreneau and coworkers ${ }^{10}$ compared the results of wedge resection in 102 patients with T1 N0 NSCLC with the results of lobectomy in 117 similar patients. They reported a 5-year survival of 58\% in patients treated with open wedge resection, $65 \%$ in patients treated with video-assisted wedge resection, and $70 \%$ in patients treated with lobectomy and concluded that lobectomy should be selected for all but poor-risk patients. After publication of these reports, it became difficult to select intentional limited resection for low-risk patients with lung cancer in the United States.
In Japan, the lung cancer mass-screening program supported by the national government under the Health and Medical Services Law for the Aged was started in 1987. ${ }^{3}$ After the nationwide implementation of this mass-screening program, sometimes combined with chest computed tomographic scanning, the number of patients given a diagnosis of small-sized lung cancer has been increasing. Faced with this situation, in 1992, Tsubota and colleagues ${ }^{11}$ began a multi-institutional clinical study of treatment of T1 N0 NSCLC (maximum tumor diameter $\leq 2 \mathrm{~cm}$ ) with segmentectomy. Fifty-five patients were enrolled in the study during the first 3 years, and among the patients followed up for a mean of 47 months, the 5-year survival exclusive of deaths unrelated to the lung cancer was $91 \%$.

Kodama and coworkers ${ }^{12}$ conducted a retrospective analysis of patients with T1 N0 M0 lung cancer, 46 of whom had undergone limited resection and 77 of whom had undergone lobectomy. They found that although the tumor diameter tended to be smaller in the limited resection group, the 5-year survival was higher in the limited resection group (93\% vs $88 \%$ in the lobectomy group). They therefore concluded that segmentectomy should be considered an acceptable treatment procedure in such patients.

In 1992, we began to perform intentional limited resection for patients in our institution with T1 N0 M0 lung cancer whose maximum tumor diameter was $2 \mathrm{~cm}$ or less. Although tumor diameter tended to be smaller in the limited resection group, the 5-year survival in the limited resection group of $89.1 \%$ was comparable to that in the lobectomy group $(90.1 \%)$.

Yamato and coworkers ${ }^{13}$ conducted limited resection in 36 patients with adenocarcinoma with tumors smaller than 2 $\mathrm{cm}$ that did not show a marked tendency to infiltrate, and they reported no tumor recurrence during an average follow-up period 30 months. 
It was previously thought that the incidence of local recurrence after limited resection would be higher than that after lobectomy, but recent studies, including the present study, have shown that the incidence of local recurrence after limited resection is not significantly higher than that after lobectomy. ${ }^{11,13}$

On the basis of these numerous reports, it can be concluded that some cases of T1 N0 M0 lung cancer can be completely resected by means of limited resection.

There were some reports concerning the relationship between prognosis and tumor histologic characteristics in adenocarcinoma. Noguchi and associates ${ }^{14}$ classified smallsized adenocarcinoma (tumor $\leq 2 \mathrm{~cm}$ ) into 6 types on the basis of their histopathologic features and reported that the prognosis of types A and B, characterized by replacement of the alveolar epithelium by cancer cells and absence of active fibroblastic proliferation, is good, with a postoperative 5 -year survival of $100 \%$. Suzuki and coworkers ${ }^{15}$ reported that the size of central fibrosis was an independent prognostic factor in peripheral lung adenocarcinoma.

A randomized controlled study to assess the effectiveness of limited resection compared with lobectomy in the treatment of T1 N0 M0 lung cancer would be worthwhile, but there remains the question of which patients should be selected for this study, patients with a lower degree of infiltration (as judged by diagnostic imaging) or patients with small tumor diameters.

\section{References}

1. Ginsberg RJ. Limited resection in the treatment of Stage I non-small cell lung cancer; an overview. Chest. 1989;96:50S-1S.
2. Ginsberg RJ, Rubinstein LV, for the Lung Cancer Study Group. Randomized trial of lobectomy versus limited resection for T1 N0 non-small cell lung cancer. Ann Thorac Surg. 1995;60:615-23.

3. Sobue T, Suzuki T, Naruke T. A case-control study for evaluation lung-cancer screening in Japan. Int J Cancer. 1992;50:230-7.

4. Sone S, Takahashi S, Li F, Yang Z, Honda T, Maruyama Y, et al. Mass screening for lung cancer with mobile spiral computed tomography scanner. Lancet. 1998;351:1242-5.

5. Koike T, Terashima M, Takizawa T, Haga M, Kurita Y, Yokoyama A, et al. The influence of lung cancer mass screening on surgical results. Lung Cancer. 1999;24:75-80.

6. Errett LE, Wilson J, Chiu RC, Munto DD. Wedge resection as an alternative procedure for peripheral bronchogenic carcinoma in poorrisk patients. J Thorac Cardiovasc Surg. 1985;90:656-61.

7. Pastorino U, Valente M, Bedini V, Infante M, Tavecchio L, Ravasi G. Limited resection for stage I lung cancer. Eur J Surg. 1991;17:42-6.

8. Read RC, Yoder G, Schaeffer RC. Survival after conservative resection for T1 N0 M0 non-small cell cancer. Ann Thorac Surg. 1990; 49:391-400

9. Warren WH, Faber LP. Segmentectomy versus lobectomy in patients with stage I pulmonary carcinoma. J Thorac Cardiovasc Surg. 1994; 107:1087-94

10. Landreneau RJ, Sugarbaker DJ, Mack MJ, Hazelrigg SR, Luketich JD, Fetterman L, et al. Wedge resection versus lobectomy for stage I (T1 N0 M0) non-small-cell lung cancer. $J$ Thorac Cardiovasc Surg. 1997;113:691-700.

11. Tsubota N, Ayabe K, Doi O, Mori T, Namikawa S, Taki T, et al. Ongoing prospective study of segmentectomy for small lung tumors. Ann Thorac Surg. 1998;66:1787-90.

12. Kodama K, Doi O, Higashiyama M, Yokouchi H. Intentional limited resection for selected patients with T1 N0 M0 non-small cell lung cancer: a single-institution study. J Thorac Cardiovasc Surg. 1997; 114:347-53.

13. Yamato Y, Tsuchida M, Watanabe T, Aoki T, Koizumi N, Umezu H, et al. Early results of a prospective study of limited resection for bronchioalveolar adenocarcinoma of the lung. Ann Thorac Surg. 2001; 71:971-4.

14. Noguchi M, Morikawa A, Kawasaki M, Matsuno Y, Yamada T, Hirohashi S, et al. Small adenocarcinoma of the lung. Cancer. 1995; 75:2844-52.

15. Suzuki K, Yokose T, Yoshida J, Nishimura M, Takahashi K, Nagai K, et al. Prognostic significance of the size of central fibrosis in peripheral adenocarcinoma of the lung. Ann Thorac Surg. 2000;69:893-7. 